\title{
Copper-Containing Carbon Feedstock for Growing Superclean Graphene
}

Kaicheng Jia ${ }^{+, \Phi}$, Jincan Zhang ${ }^{+,,,}, \operatorname{Li~Lin}^{+, \Phi}$, Zhenzhu $\mathrm{Li}^{\S}$, Jing Gao ${ }^{\S}$, Luzhao Sun ${ }^{+, \neq}$, Ruiwen

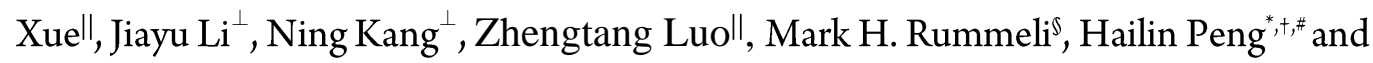
Zhongfan Liu ${ }^{*},+, \#$

${ }^{\dagger}$ Center for Nanochemistry, Beijing Science and Engineering Center for Nanocarbons, Beijing National Laboratory for Molecular Sciences, College of Chemistry and Molecular Engineering, Peking University, Beijing 100871, People's Republic of China

${ }^{\ddagger}$ Academy for Advanced Interdisciplinary Studies, Peking University, Beijing 100871, People’s

Republic of China

${ }^{\S}$ Soochow Institute for Energy and Materials InnovationS, Soochow University, Suzhou 215006, People’s Republic of China

${ }^{\perp}$ Beijing Key Laboratory of Quantum Devices, Key Laboratory for the Physics and Chemistry of Nanodevices, and Department of Electronics, Peking University, Beijing 100871, People's Republic of China

"Department of Chemical and Biological Engineering, Hong Kong University of Science and Technology, Clear Water Bay, Hong Kong SAR 999077, People’s Republic of China

"Beijing Graphene Institute (BGI), Beijing 100095, People's Republic of China

${ }^{9}$ These authors contributed equally to this work

*Correspondence: hlpeng@pku.edu.cn; zfliu@pku.edu.cn 


\section{Experiments and characterization}

Chemical vapor deposition (CVD) growth of superclean graphene film by $\mathrm{Cu}(\mathrm{OAc})_{2}$. The superclean graphene was synthesized in a low-pressure CVD (LPCVD) system, where $\mathrm{Cu}(\mathrm{OAc})_{2}$ powder $(50 \mathrm{mg})$ was loaded in a quartz boat in the upstream and the electrochemical polished $\mathrm{Cu}$ foil $(25 \mu \mathrm{m}$ thick, $99.8 \%$, Alfa Aesar 46365\#) was loaded downstream in one 1in.-diameter quartz tube, but with two independent heating systems (Figure S1a, b). Two independent heating systems with center distance of the hot zones being $28 \pm 5 \mathrm{~cm}$ were used to heat carbon feedstock and $\mathrm{Cu}$ foil in the quartz tube, respectively. Firstly, the $\mathrm{Cu}$ foil was heated to $1020{ }^{\circ} \mathrm{C}$ and annealing both in $\mathrm{H}_{2}$ atmosphere (100 sccm, $\left.\sim 120 \mathrm{~Pa}, 0.5 \mathrm{~h}\right)$ to eliminate the surface oxide and contamination. Subsequently, $\mathrm{Cu}(\mathrm{OAc})_{2}$ was heated to $220^{\circ} \mathrm{C}(\sim 122 \mathrm{~Pa}$ with 2 Pa partial pressure from $\left.\mathrm{Cu}(\mathrm{OAc})_{2}\right)$ to supply carbon source for graphene growth on $\mathrm{Cu}$ surface for $5 \mathrm{~min}$. Then, the sample was pulled out of the high-temperature region to quickly cool down to room temperature. Meanwhile, the flow rate of hydrogen was increased to $500 \mathrm{sccm}(\sim 450 \mathrm{~Pa})$ to blow away the extra carbon feedstock (Figure S1c).

a

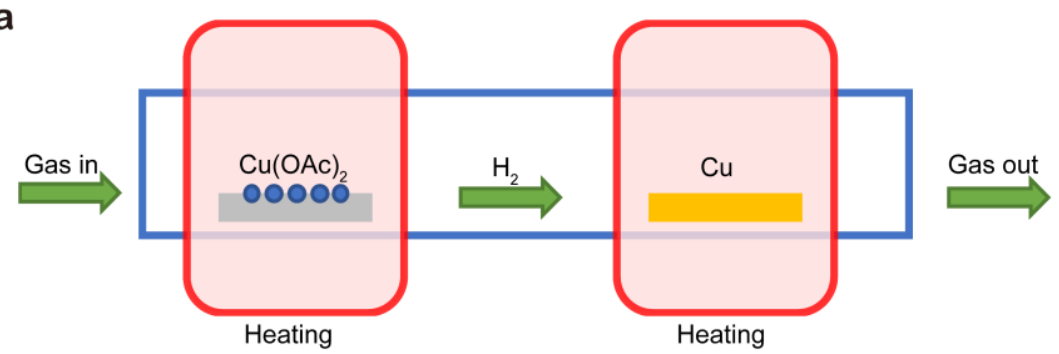

b
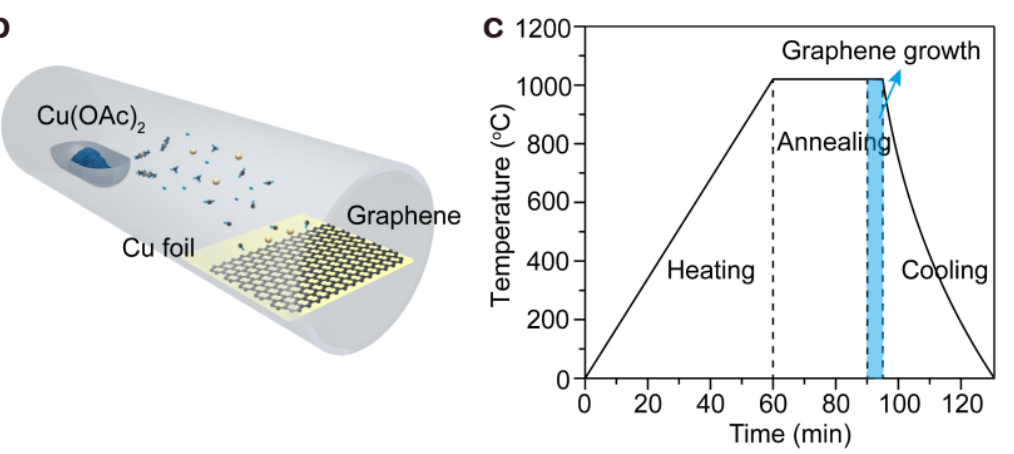

Figure S1. Growth of superclean graphene using $\mathrm{Cu}(\mathrm{OAc})_{2}$ as carbon feedstock. (a) Sketch of the homemade LPCVD system with two independent heating systems. (b) Schematic of the CVD growth of superclean graphene using $\mathrm{Cu}(\mathrm{OAc})_{2}$. (c) $\mathrm{CVD}$ process for the preparation of superclean graphene film.

To quantitatively evaluate the pyrolysis properties of $\mathrm{Cu}(\mathrm{OAc})_{2}$ and find the optimized heating 
temperature for its evaporation without decomposition, we took thermogravimetric-mass spectrometry (TG-MS) characterization of $\mathrm{Cu}(\mathrm{OAc})_{2}$. The TG-MS result was acquired with the heating temperature ranging from $40{ }^{\circ} \mathrm{C}$ to $460{ }^{\circ} \mathrm{C}$ in $\mathrm{He}$ atmosphere. The black TG profile in Figure S2a showed that the dehydration reaction happened at the temperature of $\sim 120{ }^{\circ} \mathrm{C}$, followed by the evaporation of the $\mathrm{Cu}(\mathrm{OAc})_{2}$ in the temperature ranged from $210^{\circ} \mathrm{C}$ to $260^{\circ} \mathrm{C}$. Subsequently, the dramatic slope change of the TG profile and appearance of the $\mathrm{CH}_{3}, \mathrm{CO}_{2}, \mathrm{HAc}$ and $\mathrm{Cu}$ ions, all indicated that a new decomposition reaction occur. And the decomposition temperature ranged from $260{ }^{\circ} \mathrm{C}$ to $300{ }^{\circ} \mathrm{C}$. After TG analysis (TGA) measurement, there is $\sim 8 \%$ mass remains in the crucible, which was collected and proved to be residual $\mathrm{Cu}$ particles using scanning electron microscopy (SEM) and energy dispersion spectrum (EDS) characterization.

In our actual CVD process, the heating temperature of $\mathrm{Cu}(\mathrm{OAc})_{2}\left(\sim 220^{\circ} \mathrm{C}\right)$ was precisely controlled below its decomposition temperature $\left(\sim 260^{\circ} \mathrm{C}\right)$. Thus, $\mathrm{Cu}(\mathrm{OAc})_{2}$ molecules would be evaporated without being decomposed. The single peak in the gas chromatography (GC) spectrum measured at a fixed heating temperature of $220^{\circ} \mathrm{C}$ verified the evaporation of $\mathrm{Cu}(\mathrm{OAc})_{2}$ as a whole without decomposition, which agreed well with appearance of peaks corresponding to $\mathrm{m} / \mathrm{z}$ ranging from 63 to 166 in the spectrum in the MS spectra in Figure S2f.
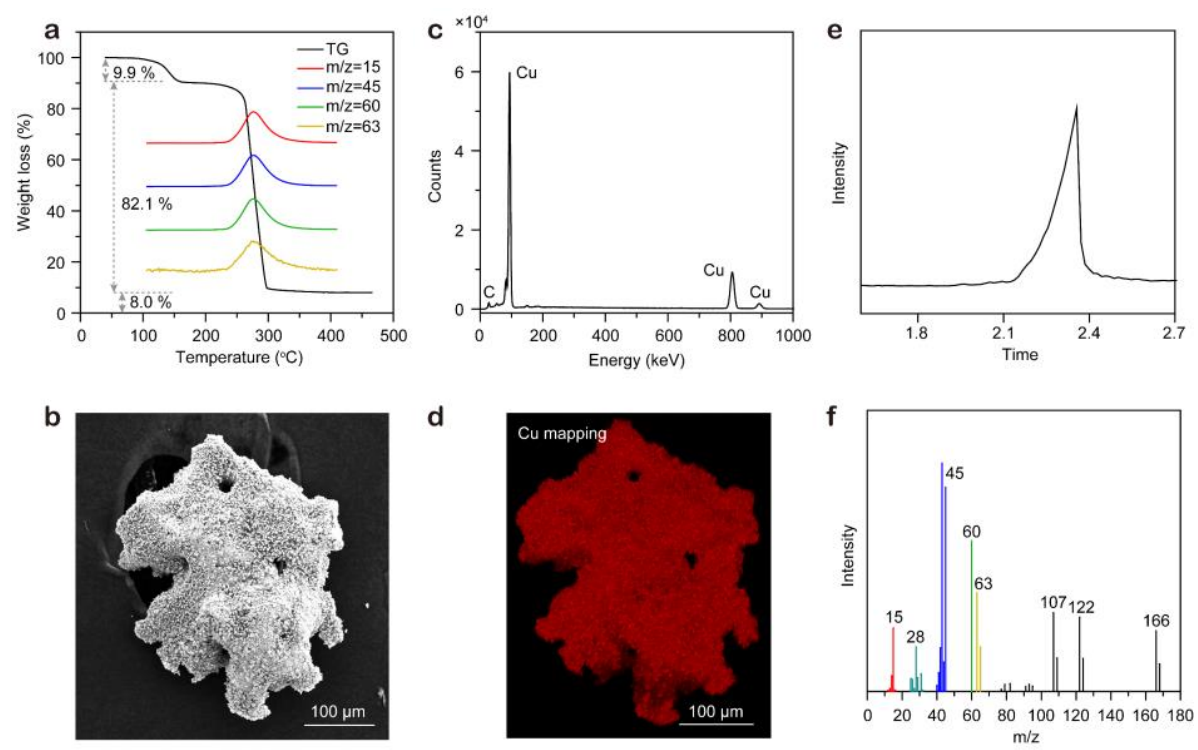

Figure S2. Pyrolytic feature of $\mathrm{Cu}(\mathrm{OAc})_{2}$. (a) TG-MS spectra of the $\mathrm{Cu}(\mathrm{OAc})_{2}$, where the black line was TG spectra ranging from 40 to $460^{\circ} \mathrm{C}$ and the red, blue, green and orange lines were charge to mass ratio profiles of the characteristic ions. (b) SEM image of the remaining species after TGA measurement. (c) 
EDS result of the particle in (b). (d) Corresponding Cu element mapping of (b). (e) GC spectrum collected at the temperature about $220^{\circ} \mathrm{C}$. (f) MS spectra of the products in (e).

Growth of graphene film by $\mathrm{CH}_{4}$. The ordinary unclean graphene was grown by the LPCVD method with $\mathrm{CH}_{4}$ as the carbon feedstock. The $\mathrm{Cu}$ foil $(25 \mu \mathrm{m}$ thick, 99.8\%, Alfa Aesar 46365\#) after electrochemical polishing was placed in a 1 in.-diameter quartz tube. The system was heated to $1020{ }^{\circ} \mathrm{C}$ with $\mathrm{H}_{2}(100$ sccm, $\sim 120 \mathrm{~Pa}$ ) and then maintained $0.5 \mathrm{~h}$ for $\mathrm{Cu}$ annealing in $\mathrm{H}_{2}(100 \mathrm{sccm}, \sim 120 \mathrm{~Pa})$. Subsequently, $\mathrm{CH}_{4}(1 \mathrm{sccm}, \sim 122 \mathrm{~Pa})$ was introduced to initiate the graphene growth. After graphene growth, the sample was pulled out of the high-temperature region to quickly cool down to room temperature and $\mathrm{H}_{2}$ and $\mathrm{CH}_{4}$ were maintained to avoid the etching of graphene.

Graphene transfer. To confirm the intrinsic cleanness of graphene by transmission electron microscopy (TEM) characterization, the graphene samples were transferred onto TEM grid using the reported polymer-free transfer method to exclude the interference of polymer residues. ${ }^{1}$ While for characterizations based on $\mathrm{SiO}_{2} / \mathrm{Si}$ and quartz substrates, the poly (methyl methacrylate) (PMMA)assisted transfer method was utilized. First, the graphene film was spin-coated with PMMA at $2000 \mathrm{rpm}$ and baked at $170{ }^{\circ} \mathrm{C}$ for $3 \mathrm{~min}$. Then, the unwanted graphene on the other side of the $\mathrm{Cu}$ foil was etched using air plasma treatment, followed by the $\mathrm{Cu}$ etching using $1 \mathrm{M} \mathrm{Na}_{2} \mathrm{~S}_{2} \mathrm{O}_{8}$ or $\mathrm{FeCl}_{3}$ solution. After that, the as-obtained free-standing PMMA/graphene film, which was thoroughly rinsed with deionized water, was transferred onto target substrates and dried. Finally, PMMA was removed using hot acetone.

Characterization. Optical microscopy (OM) images were acquired using an Olympus BX51 microscopy. Raman spectra were obtained using LabRAM HR-800 with laser wavelength of $514 \mathrm{~nm}$ and $\times 100$ objective. Raman mapping results were obtained with RAMAN-11 using $532 \mathrm{~nm}$ laser (Nanophoton, Japan). SEM images and EDS were obtained with SEM (Hitachi S-4800, acceleration voltage 5-30 kV). TEM images were acquired with FEI Tecnai F30 electron microscope (acceleration voltage $300 \mathrm{kV}$ ). Aberration-corrected TEM images were acquired with Titan 60-300 electron microscope (monochromated mode at $80 \mathrm{kV}$ ). Energy dispersive X-ray (EDX) spectra and high angle annular dark field (HAADF) images were acquired using scanning transmission electron microscope (STEM) mode at $60 \mathrm{kV}$ in a double corrected FEI Titan Themis G2 electron microscope. Atomic force microscopy (AFM) characterization was carried out on Bruker dimension icon microscopy using the Scanasyst mode. Time-of-flight secondary ion mass spectrometry (ToF-SIMS) spectra were collected by ToF (ToF-SIMS 
V, ION-TOF GmbH, Munster, Germany) with a $\mathrm{Bi}^{3+}$ beam operating at $25 \mathrm{keV}$. Thermogravimetric-mass spectrometry (TG-MS) were obtained by TG-MS (Hyphenation of TG/FTIR/GCMS, PerKinElmer, EI $70 \mathrm{eV})$. Optical transmittance spectra were collected by a Perkin-Elmer Lambda 950 UV-vis spectrophotometer. The element analysis was performed by X-ray photoelectron spectroscopy (XPS) (Kratos Analytical AXIS-Ultra with monochromatic Al K $\alpha$ X-ray). Sheet resistance of the graphene film was measured using four-probe resistance measuring meter (Guangzhou 4-probe Tech Co. Ltd., RTS-4) based on four-point probes method to eliminate contact resistance.

Graphene device fabrication and transport measurements. Graphene samples grown by $\mathrm{Cu}(\mathrm{OAc})_{2}$ were transferred onto $\mathrm{SiO}_{2} / \mathrm{Si}$ substrates with 300-nm-thick oxide layer and alignments marks. After graphene transfer, AFM was utilized to check the flatness of samples. Electron-beam lithography (EBL) (Raith 150 2nd) and reactive ion etching (RIE) with $\mathrm{O}_{2}$ (Trion Technology Minilock III) were employed for graphene pattern with designed geometry. After a PMMA mask (PMMA 950K A4 @ 4000 rpm) patterned by EBL, $10 \mathrm{~nm}$ Pd and $80 \mathrm{~nm}$ Au electrodes were deposited on the graphene samples by electron-beam evaporation (Kurte J. Lesker AXXIS). Electrical characterization at room temperature was performed in a vacuum probe station (Lakeshore TTP-4) with a Keithly Semiconductor Characterization System (Model 4200-SCS).

Friction force measurements. Friction of transferred graphene was measured in air on Bruker dimension icon microscopy using the Contact mode fitted with AFM tip ( $\csc 17$, Mikromasch). During measurement, parameters of Integral gain and Proportional gain were adjusted to make trace line and retrace line coincide with each other for clear height and friction image of the samples.

Calculation method. All the structural optimizations were carried out by using the density-functional theory (DFT) method implemented in the Vienna ab initio simulation package (VASP) to their lowest energy positions. The projected augmented wave (PAW) pseudopotentials was adopted to describe the interactions between general gradient approximation (GGA) parametrized by Perdew-Burke-Ernzerhof (PBE), which was used as the exchange correlation function. The wave functions at each k-point were expanded with a plane wave basis set and the kinetic cutoff energy is $520 \mathrm{eV}$. The electron occupancies were determined according to a Methfessel-Paxton scheme with an energy smearing of $0.2 \mathrm{eV}$. All structures were optimized by a conjugate gradient method until the force component on every atom was less than $0.01 \mathrm{eV} / \AA$. 


\section{Typical TEM images of graphene using different carbon feedstocks}

$\mathrm{Cu}(\mathrm{OAc})_{2}$ and $\mathrm{CH}_{4}$ were respectively used as carbon feedstocks to grow graphene films in the LPCVD system, which were transferred onto 3-mm-sized holey TEM grid without the assistance of polymer to exclude the influence of polymer residues and evaluate their intrinsic cleanness. The representative TEM images of graphene film with different carbon feedstocks were presented in Figure S3. Note that, the regions with bright contrast correspond to the clean graphene, while the darker contrast is caused by the existence of amorphous carbon.
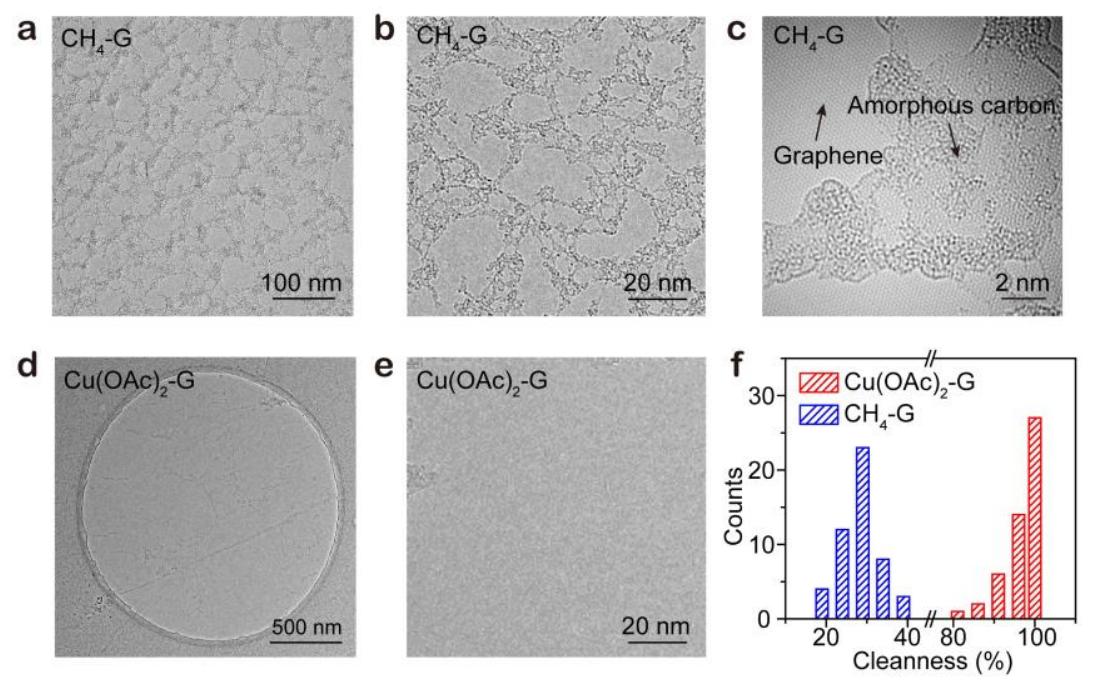

Figure S3. Typical TEM images of graphene grown by different carbon feedstocks. (a-c) Representative TEM images of graphene film grown by $\mathrm{CH}_{4}$ with different magnifications. (d-e) Representative TEM images of graphene film grown by $\mathrm{Cu}(\mathrm{OAc})_{2}$ with different magnifications. (f) Statistical results of cleanness of the graphene film grown by $\mathrm{Cu}(\mathrm{OAc})_{2}$ (red) and $\mathrm{CH}_{4}$ (blue).

\section{High-quality monolayer graphene film grown by $\mathrm{Cu}(\mathrm{OAc})_{2}$}

$\mathrm{OM}$ and Raman characterization confirmed high uniformity and crystallinity of the $\mathrm{Cu}(\mathrm{OAc})_{2}$-derived monolayer graphene film transferred onto a $\mathrm{SiO}_{2} / \mathrm{Si}$ substrate, as shown in Figure S4. In detail, both the Raman spectra in Figure $\mathrm{S} 4 \mathrm{~b}$ and $\mathrm{I}_{\mathrm{D}} / \mathrm{I}_{\mathrm{G}}$ mapping results in Figure $\mathrm{S} 4 \mathrm{c}$ exhibited a noise-level D-band intensity, verifying the ability of $\mathrm{Cu}(\mathrm{OAc})_{2}$ in the growth of high-quality, defect-free monolayer graphene film. 

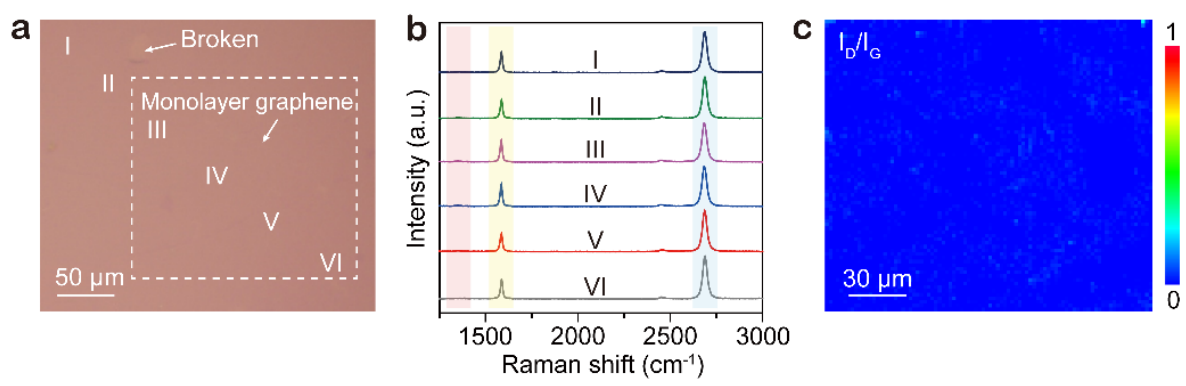

Figure S4. OM and Raman characterization of graphene film grown by $\mathrm{Cu}(\mathrm{OAc})_{2}$. (a) $\mathrm{OM}$ image of the as-grown graphene film transferred onto a $\mathrm{SiO}_{2} / \mathrm{Si}$ substrate. (b) Raman spectra of the points and (c) $\mathrm{I}_{\mathrm{D}} / \mathrm{I}_{\mathrm{G}}$ mapping of the square region marked in (a).

\section{Visualization of the amorphous carbon contamination with the assistance of $\mathrm{TiO}_{2}$ nanoparticles.}

Visualization of amorphous carbon contamination on graphene surface can be achieved by putting the graphene/Cu samples above the freshly prepared $\mathrm{TiO}_{2}$ fog, which was formed based on the following chemical reaction:

$$
\mathrm{TiCl}_{4}+2 \mathrm{H}_{2} \mathrm{O} \rightarrow \mathrm{TiO}_{2}+4 \mathrm{HCl}
$$

To confirm the selective adsorption of $\mathrm{TiO}_{2}$ particles on amorphous carbon regions, TEM characterization was conducted to give the evidence that $\mathrm{TiO}_{2}$ could be used to identify the existence of amorphous carbon on graphene surface. As shown in Figure S5, the spatial distribution of the asdeposited $\mathrm{TiO}_{2}$ on the graphene surface was determined using EDX mapping of $\mathrm{C}$, Ti and $\mathrm{O}$ elements. In HAADF-STEM image, the $\mathrm{TiO}_{2}$ decorated region (stronger Ti and $\mathrm{O}$ signals) displayed a bright $\mathrm{C}$ signals, which indicated the presence of amorphous carbon contamination.
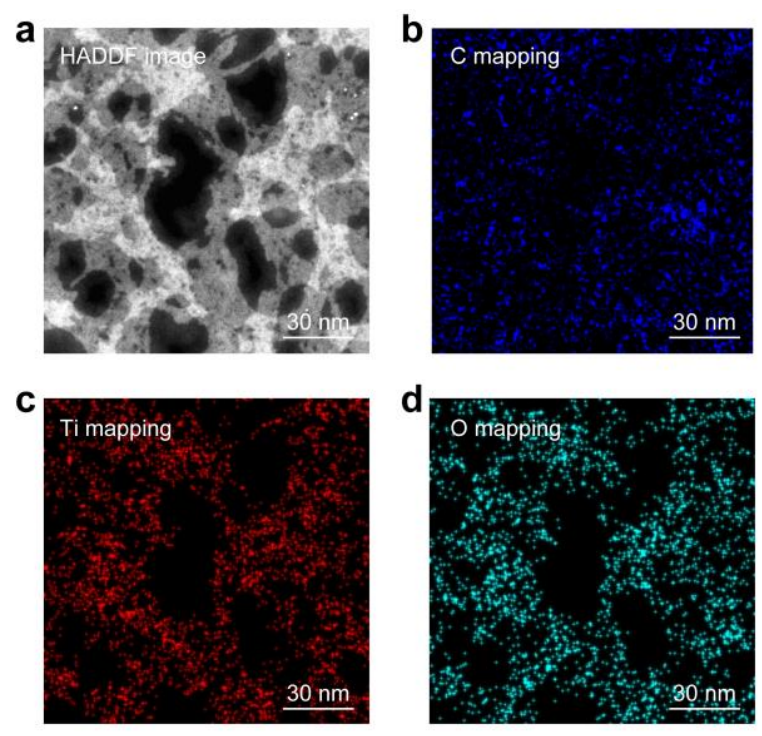
Figure S5. Selective adsorption of $\mathrm{TiO}_{2}$ on the contaminated regions of graphene surface. (a) HADDFSTEM images of graphene on TEM grid after $\mathrm{TiO}_{2}$ deposition. (b-d) Corresponding EDX mapping of C (b), Ti (c) and $\mathrm{O}(\mathrm{d})$ elements in (a).

As shown in Figure S6a, the contaminated regions of graphene surface would adsorb more $\mathrm{TiO}_{2}$ nanoparticles than the clean regions, which may be attributed to the presence of abundant dangling bonds in amorphous carbon contamination. As indicated by the dark field OM images of graphene film grown by $\mathrm{Cu}(\mathrm{OAc})_{2}$ and $\mathrm{CH}_{4}$ (Figure $\mathrm{S} 6 \mathrm{~b}$ and $\mathrm{c}$ ), the clear difference of the number of adsorbed $\mathrm{TiO}_{2}$ nanoparticles further proved the improved cleanness of graphene grown by $\mathrm{Cu}(\mathrm{OAc})_{2}$.
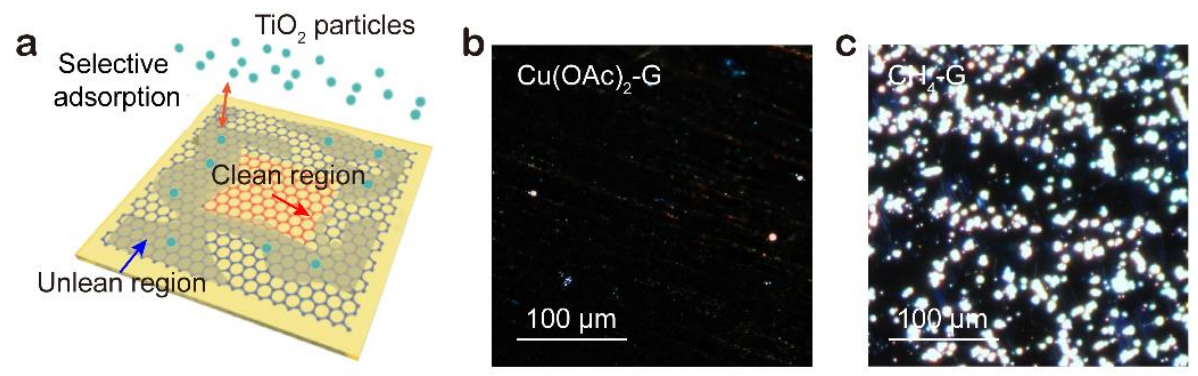

Figure S6. $\mathrm{TiO}_{2}$ visualization of graphene cleanness grown by $\mathrm{Cu}(\mathrm{OAc})_{2}$ and $\mathrm{CH}_{4}$. (a) Illustration scheme of the selective deposition of $\mathrm{TiO}_{2}$ nanoparticles on contaminated regions of graphene/Cu surface. (b-c) Dark field OM images of graphene grown by $\mathrm{Cu}(\mathrm{OAc})_{2}(\mathrm{~b})$ and $\mathrm{CH}_{4}(\mathrm{c})$ after $\mathrm{TiO}_{2}$ visualization.

\section{Verification of the advantage of $\mathrm{Cu}(\mathrm{OAc})_{2}$ with the assistance of isotopic carbon source}

To confirm the advantage of $\mathrm{Cu}(\mathrm{OAc})_{2}$ for the growth of superclean graphene and exclude the influence of other factors for graphene cleanness evaluation, we alternately supply $\mathrm{Cu}(\mathrm{OAc})_{2}$ and ${ }^{13} \mathrm{C}$-labeled $\mathrm{CH}_{4}$ to grow graphene on one $\mathrm{Cu}$ foil, with the former one to initiate graphene nucleation and the latter one for further epitaxial growth (Figure S7a). Raman mapping results of the graphene film transferred onto a $\mathrm{SiO}_{2} / \mathrm{Si}$ substrate confirmed the existence of ${ }^{12} \mathrm{C}$-graphene domain grown by $\mathrm{Cu}(\mathrm{OAc})_{2}$ and ${ }^{13} \mathrm{C}$ graphene outer layer grown by $\mathrm{CH}_{4}{ }^{2}$ The as-obtained graphene film was further used for $\mathrm{TiO}_{2}$ visualization to evaluate the cleanness. 

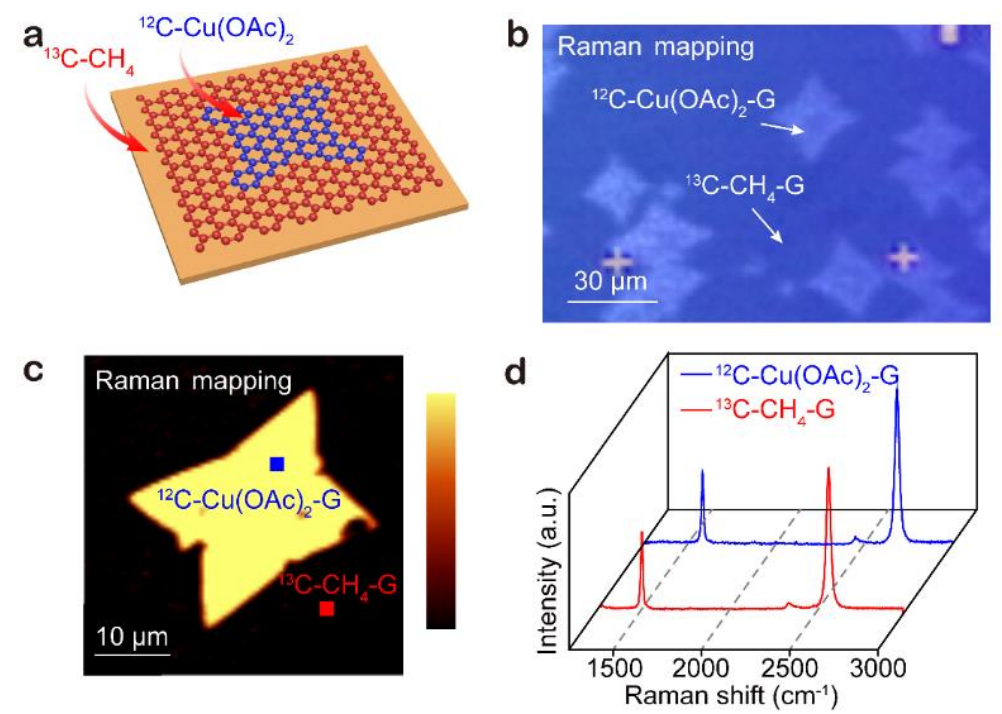

Figure S7. Structure of $\mathrm{Cu}(\mathrm{OAc})_{2}$-grown nuclei and $\mathrm{CH}_{4}$-grown outer layer. (a) Schematic of the growth of graphene film, where $\mathrm{Cu}(\mathrm{OAc})_{2}$ was used to initiate the nucleation of graphene and ${ }^{13} \mathrm{C}$-labeled $\mathrm{CH}_{4}$ was used for further epitaxial growth. (b) Typical Raman mapping result of the as-obtained graphene film transferred onto a $\mathrm{SiO}_{2} / \mathrm{Si}$ substrate with wavelength ranging from 2640 to $2760 \mathrm{~cm}^{-1}$ (corresponding to $2 \mathrm{D}$ peak in ${ }^{12} \mathrm{C}$-graphene), and the graphene domains (light blue in the picture) were convinced to be formed by $\mathrm{Cu}(\mathrm{OAc})_{2}$. (c) Raman mapping result of the graphene domain and (d) Raman spectra of the points marked in (c).

\section{XPS characterizations of the additional supply of $\mathrm{Cu}$ by $\mathrm{Cu}(\mathrm{OAc})_{2}$}

To confirm the additional $\mathrm{Cu}$ supply by $\mathrm{Cu}(\mathrm{OAc})_{2}$, porous $\mathrm{Al}_{2} \mathrm{O}_{3}$ molecular sieves were used to collect the species in the gas phase in the LPCVD system with $\mathrm{Cu}(\mathrm{OAc})_{2}$ and $\mathrm{CH}_{4}$ as carbon feedstock, respectively (Figure S8a). Here, a new quartz tube was employed for this experiment and no $\mathrm{Cu}$ foil was inserted, in order to exclude other possible origins of $\mathrm{Cu}$ species. Clearly, the $\mathrm{Al}_{2} \mathrm{O}_{3}$ molecular sieve displayed a clear red color when $\mathrm{Cu}(\mathrm{OAc})_{2}$ was used (Figure $\mathrm{S} 8 \mathrm{~b}$ ), indicating the appearance of abundant $\mathrm{Cu}$ species in the gas phase when $\mathrm{Cu}(\mathrm{OAc})_{2}$ was used, which was also evident in the obvious $\mathrm{Cu}$ signals in the XPS spectrum (Figure S8c). 

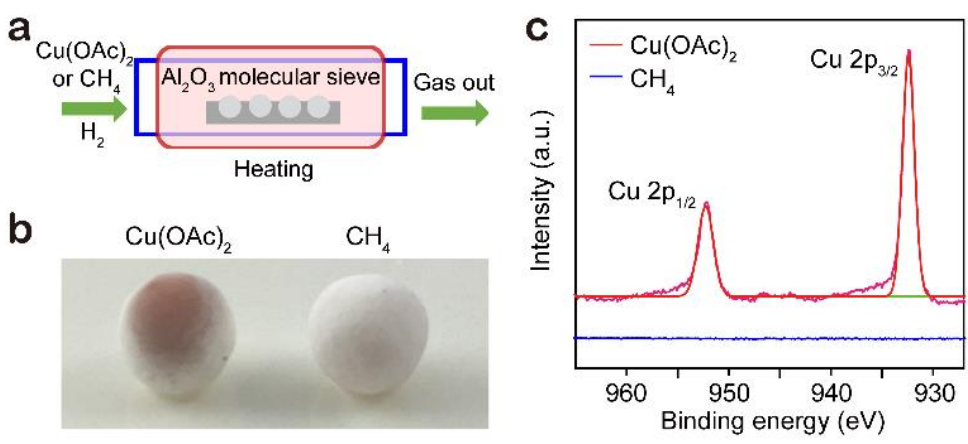

Figure S8. Confirmation of the additional $\mathrm{Cu}$ supply by $\mathrm{Cu}(\mathrm{OAc})_{2}$. (a) Schematic of the collection of the species in the gas phase using $\mathrm{Al}_{2} \mathrm{O}_{3}$ molecular sieves. (b) Photograph of $\mathrm{Al}_{2} \mathrm{O}_{3}$ molecular sieves after collection of gas-phase species using $\mathrm{Cu}(\mathrm{OAc})_{2}$ (left) and $\mathrm{CH}_{4}$ (right) as carbon feedstocks. (c) XPS spectra of the collected species in the LPCVD system.

To compare the content of $\mathrm{Cu}$ vapor in the actual graphene growth CVD process, we collected the species in the gas phase using $\mathrm{Cu}(\mathrm{OAc})_{2}$ and $\mathrm{CH}_{4}$ as carbon feedstocks, respectively, in the presence of $\mathrm{Cu}$ foil. In the growth of graphene using $\mathrm{Cu}(\mathrm{OAc})_{2}$ as the carbon source, $\mathrm{Al}_{2} \mathrm{O}_{3}$ molecular sieves displayed an obvious deeper red color while only light red color was observed when $\mathrm{CH}_{4}$ was used, indicating the limited $\mathrm{Cu}$ vapor provided by $\mathrm{Cu}$ foil during graphene growth (Figure S9a). SEM and EDS characterizations were further conducted to provide more information about the morphologies and elementary composition of the collected species on $\mathrm{Al}_{2} \mathrm{O}_{3}$ molecular sieves (Figure S9b-d). When $\mathrm{Cu}(\mathrm{OAc})_{2}$ was used as carbon feedstock, there was dense distribution of $\mathrm{Cu}$ nanoparticles on the surface of $\mathrm{Al}_{2} \mathrm{O}_{3}$ molecular sieves. In contrast, the content of the detected $\mathrm{Cu}$ species when using $\mathrm{CH}_{4}$ as the carbon source was significantly reduced (Figure S9e-f).
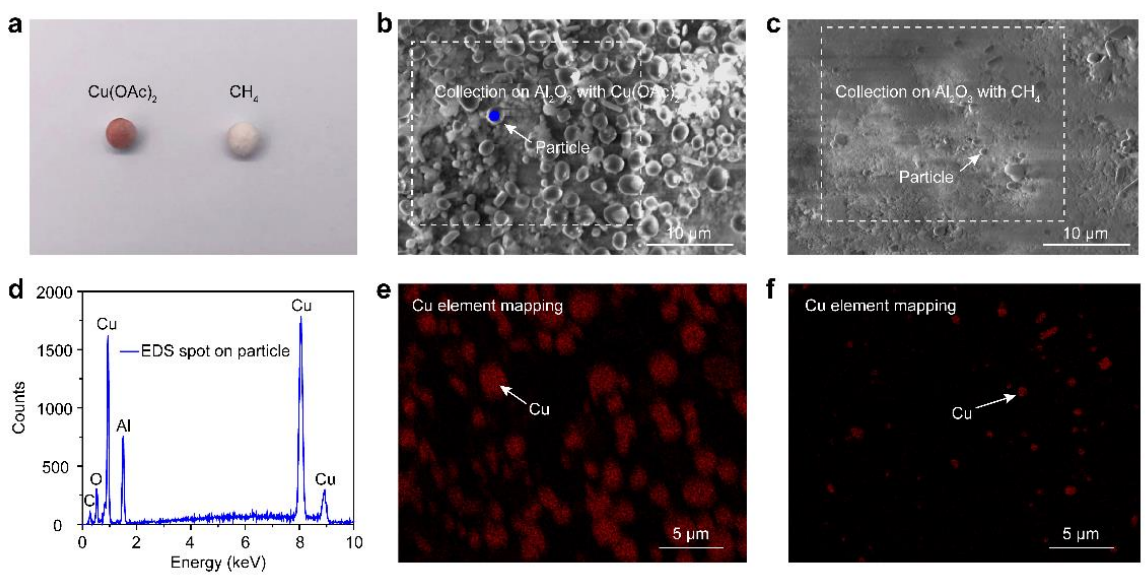
Figure S9. Confirmation of the abundant $\mathrm{Cu}$ supply by $\mathrm{Cu}(\mathrm{OAc})_{2}$. (a) Photograph of $\mathrm{Al}_{2} \mathrm{O}_{3}$ molecular sieves after collection of gas-phase species using $\mathrm{Cu}(\mathrm{OAc})_{2}$ (left) and $\mathrm{CH}_{4}$ (right) as carbon feedstocks with $\mathrm{Cu}$ foil. (b) $\mathrm{SEM}$ image of collection on $\mathrm{Al}_{2} \mathrm{O}_{3}$ molecular sieve with $\mathrm{Cu}(\mathrm{OAc})_{2}$ as carbon feedstock. (c) SEM image of collection on $\mathrm{Al}_{2} \mathrm{O}_{3}$ molecular sieve with $\mathrm{CH}_{4}$ as carbon feedstock. (d) EDS spectrum of the particle marked with blue pot in (b). (e-f) Cu element mapping in the corresponding regions marked white dotted frame in (b) and (c).

\section{Theoretical investigation of $\mathrm{Cu}$ vapor in the enhancement of the cleanness of graphene}

In the ordinary CVD synthesis of graphene film, since $\mathrm{Cu}$ vapor was insufficient in the gas phase, dehydrogenation of carbon feedstock in the boundary layer was mainly caused by thermal decomposition rather than catalytic decomposition. In this case, the incomplete decomposition of carbon species in the boundary layer would result in the formation of amorphous carbon contamination on graphene surface. In contrast, with the sufficient supply of $\mathrm{Cu}$ catalyst to the gas phase reaction in the boundary layer, the dehydrogenation of carbon species would be greatly promoted and clean graphene film could be successfully synthesized.

In fact, both the decreased energy barrier for $\mathrm{CH}_{4}$ decomposition with the catalyzation of $\mathrm{Cu}$ and the sufficient $\mathrm{Cu}$ vapor supplied by $\mathrm{Cu}$-containing carbon feedstock contributed to the improved cleanness of graphene film. From the viewpoint of reaction kinetics equation, the reaction rate of $\mathrm{CH}_{\mathrm{x}}$ decomposition can be seen as the sum of the catalyst decomposition rate $(k)$ and thermal decomposition rate $\left(k^{\prime}\right)$ :

$$
v=k * p\left(\mathrm{CH}_{\mathrm{x}}\right) * p\left(\mathrm{Cu}_{\mathrm{gas}}\right)+k * p\left(\mathrm{CH}_{\mathrm{x}}\right)
$$

It is clear that both reaction constant $\left(k\right.$ and $\left.k^{\prime}\right)$ and the partial pressure of $\mathrm{Cu}$ vapor, $p\left(\mathrm{Cu}_{\mathrm{gas}}\right)$,would influence the reaction rate $v$, i.e. the decomposition rate of hydrocarbon species in our experiment. Then, according to the Arrhenius equation:

$$
k=\mathrm{A} * \exp \left(-E_{\mathrm{a}} / R T\right)
$$

The higher the energy barriers $\left(E_{\mathrm{a}}\right)$ of $\mathrm{CH}_{\mathrm{i}}$ dehydrogenation reaction, the smaller the reaction constant (k). Considering that the existence of $\mathrm{Cu}$ species can significantly lower the energy barrier for $\mathrm{CH}_{\mathrm{i}}$ decomposition, the reaction rate of catalyst decomposition $(k)$ is much larger than that of the thermal 
decomposition $\left(k^{\prime}\right)$. High energy barriers of $\mathrm{CH}_{\mathrm{x}}$ decomposition without the assistance of $\mathrm{Cu}$ catalyst significantly lowered the reaction rate. Therefore, contribution of the latter part to the total reaction rate can be neglected.

For the comparison of the former part, the partial pressures of $\mathrm{Cu}$ vapor for both cases, $p\left(\mathrm{Cu}_{\mathrm{gas}} \mathrm{Cu}(\mathrm{OAc}) 2\right)$ and $p\left(\mathrm{Cu}_{\mathrm{gas}, \mathrm{CH} 4}\right)$ are calculated and compared. According to the SEM and EDX results of the gas species collected by the $\mathrm{Al}_{2} \mathrm{O}_{3}$ molecular sieves, the content of $\mathrm{Cu}$ catalyst provided by $\mathrm{Cu}(\mathrm{OAc})_{2}$ is much more than that provided only by $\mathrm{Cu}$ foil. To be quantitative, the partial pressure of $\mathrm{Cu}$ vapor with $\mathrm{Cu}(\mathrm{OAc})_{2}$ is equivalent to that of $2 \mathrm{sccm} \mathrm{CH}_{4}$, about 100 times higher than that of $\mathrm{Cu}$ vapor with only $\mathrm{Cu}$ foil $(3 \times$ $10^{-7}$ bar, i.e. $3 \times 10^{-2} \mathrm{~Pa}$, at $\left.\sim 1000^{\circ} \mathrm{C}\right)$. Therefore, in the gas phase, given the same $k$ and $p\left(\mathrm{CH}_{4}\right)$, the reaction rate with $\mathrm{Cu}(\mathrm{OAc})_{2}\left(v=k * p\left(\mathrm{CH}_{4}\right) * p\left(\mathrm{Cu}_{\mathrm{gas}, \mathrm{Cu}(\mathrm{OAc}) 2))}\right)\right.$ is much larger than the reaction rate without $\mathrm{Cu}(\mathrm{OAc})_{2}\left(v^{\prime}=k^{*} p\left(\mathrm{CH}_{4}\right) * p\left(\mathrm{Cu}_{\mathrm{gas}, \mathrm{CH} 4}\right)\right)$. Similar analysis is also applicable to the subsequent decomposition process of active carbon species such as $\mathrm{CH}_{3}, \mathrm{CH}_{2}$, and $\mathrm{CH}$. Based on the discussion above, $\mathrm{Cu}(\mathrm{OAc})_{2}$ contributed to the improved cleanness of graphene film because of the sufficient supply of $\mathrm{Cu}$ catalyst to the gas phase.

Furthermore, the decreased energy barrier for the dehydrogenation of carbon species caused by the additional supply of $\mathrm{Cu}$ vapor, was supported by the increased rate of graphene grown using $\mathrm{Cu}(\mathrm{OAc})_{2}$ compared with $\mathrm{CH}_{4}$. By carefully controlling the same molar number of the carbon species supplied by the $\mathrm{Cu}(\mathrm{OAc})_{2}$ and $\mathrm{CH}_{4}$, the growth rate of graphene using $\mathrm{Cu}(\mathrm{OAc})_{2}$ is nearly doubled in comparison with the growth rate of graphene via $\mathrm{CH}_{4}$ (Figure S10), indicating that the decomposition of carbon sources was sufficient due to the improved supply of $\mathrm{Cu}$ vapor, which also contributed to the complete decomposition of active carbon species in the boundary layer to suppress the formation of amorphous carbon
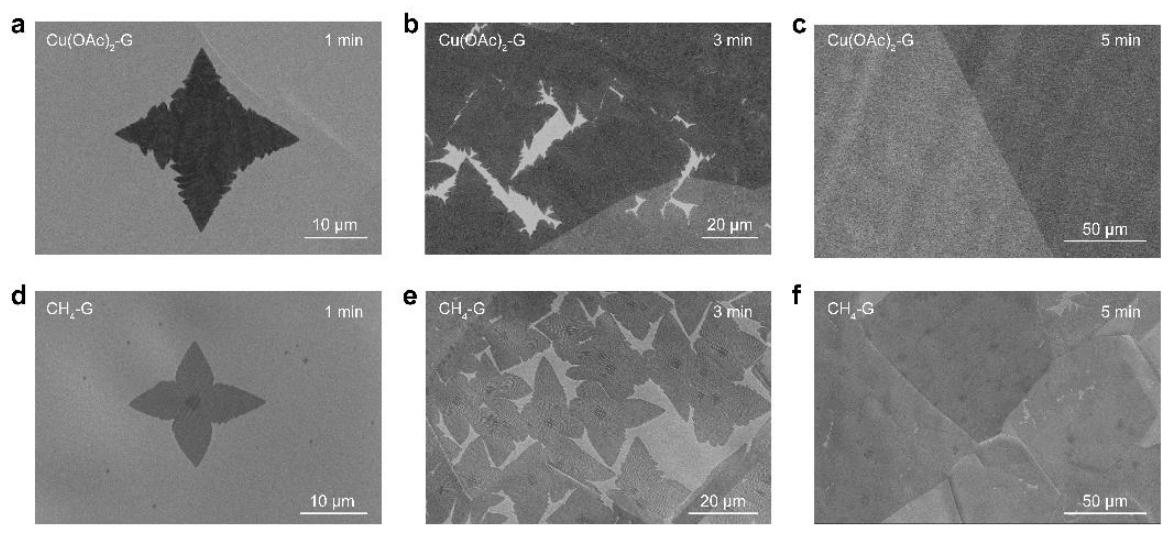
Figure S10. Growth rate of graphene with $\mathrm{Cu}(\mathrm{OAc})_{2}$ and $\mathrm{CH}_{4}$ as carbon feedstock. (a-c) SEM images of graphene grown by $\mathrm{Cu}(\mathrm{OAc})_{2}$ in $1 \mathrm{~min}(\mathrm{a}), 3 \mathrm{~min}(\mathrm{~b})$ and $5 \mathrm{~min}(\mathrm{c})$. (d-f) SEM images of graphene grown by $\mathrm{CH}_{4}$ in $1 \mathrm{~min}(\mathrm{~d}), 3 \mathrm{~min}(\mathrm{e})$ and $5 \min (\mathrm{f})$.

\section{Exclusion the effect of $\mathrm{AcO}^{-}$for the growth of superclean graphene}

To confirm that the additional $\mathrm{Cu}$ catalyst provided by $\mathrm{Cu}(\mathrm{OAc})_{2}$ is the critical factor to synthesize superclean graphene, graphene film grown by HOAc was prepared and transferred to the TEM grid for cleanness evaluation. Besides, cleanness of the graphene film grown by $\mathrm{CH}_{4}$ with addition of $\mathrm{CO}_{2}$ and graphene film grown by mixtures of $\mathrm{HOAc} / \mathrm{CH}_{4} / \mathrm{CO}_{2}$ was also characterized. Representative TEM images presented in Figure S11 showed that all the samples had no significant improvement of cleanness, further verifying the critical role of $\mathrm{Cu}$ element in the $\mathrm{Cu}(\mathrm{OAc})_{2}$ carbon feedstock in the enhancement of graphene cleanness.
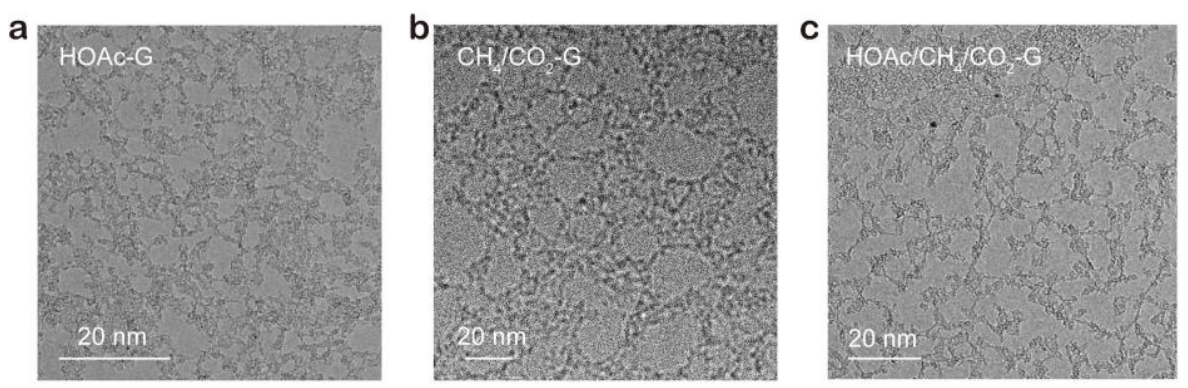

Figure S11. Typical TEM images of graphene film grown with different conditions. (a) Representative TEM image of graphene film grown by HOAc. (b) Representative TEM image of graphene film grown by $\mathrm{CH}_{4}$ with addition of $\mathrm{CO}_{2}$ during graphene growth. (c) Representative TEM image of graphene film grown by mixtures of $\mathrm{HOAc} / \mathrm{CH}_{4} / \mathrm{CO}_{2}$.

\section{PMMA residues on the surface of ordinary CVD-grown graphene after transfer}

As shown in the AFM image (Figure 12a), there were abundant PMMA residues on transferred graphene surface (Figure S12a), totally different from the clean and flat surface of the superclean graphene after transfer (Figure 3a). Besides, the height of the PMMA residues ranged from $2.4 \mathrm{~nm}$ to $6.6 \mathrm{~nm}$ on graphene surface (Figure S12b), which may cause negative impact on the property and performance of graphene film. 

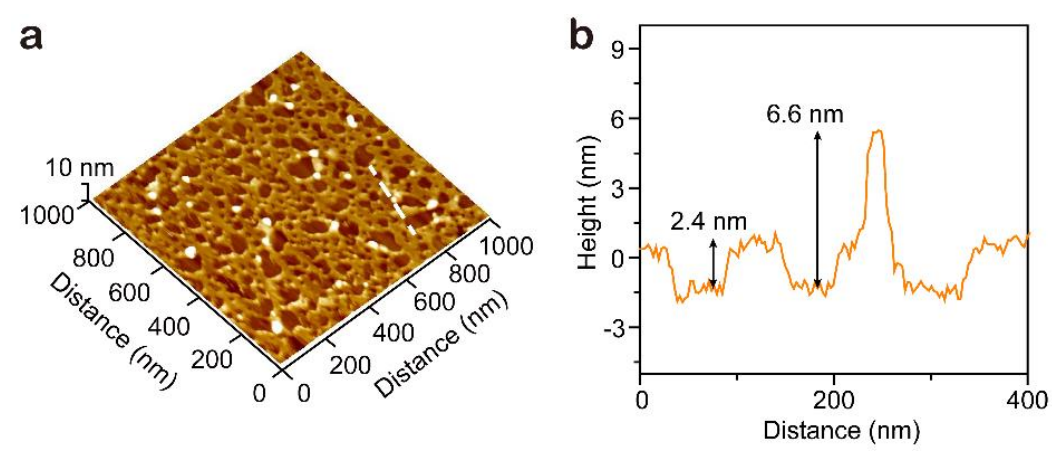

Figure S12. AFM characterization of the PMMA residues on ordinary CVD-grown graphene film after transferred onto a $\mathrm{SiO}_{2} / \mathrm{Si}$ substrate. (a) AFM image of the obvious PMMA residues on transferred graphene surface. (b) Height analysis of the polymer residues, corresponding to the white dotted line in (a).

\section{ToF-SIMS characterization of the PMMA residues on transferred graphene samples}

In order to confirm the relationship between PMMA residues and the intrinsic cleanness of graphene film, ${ }^{2} \mathrm{H}$-marked PMMA was used to transfer graphene and ToF-SIMS was conducted to quantify the amount of ${ }^{2} \mathrm{H}^{-}$, which could represent the amount of PMMA residues. ${ }^{3}$ For superclean graphene grown by $\mathrm{Cu}(\mathrm{OAc})_{2},{ }^{2} \mathrm{H}^{-}$signals were in the noise level, indicating the absence of polymer residues on graphene surface. In contrast, obvious ${ }^{2} \mathrm{H}^{-}$signals were observed in unclean graphene sample grown by $\mathrm{CH}_{4}$, indicating the abundant distribution of PMMA residues (Figure S13).

a

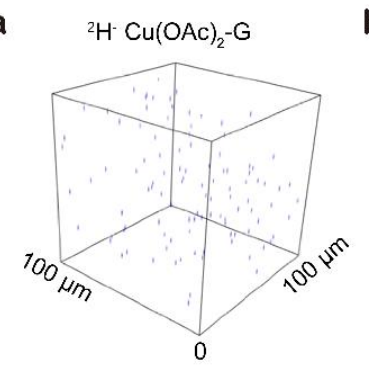

b
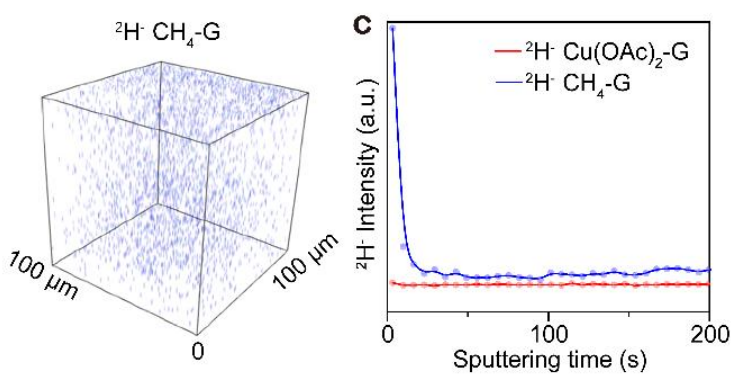

Figure S13. ToF-SIMS characterizations of the content of PMMA residues on graphene grown by $\mathrm{Cu}(\mathrm{OAc})_{2}$ and $\mathrm{CH}_{4}$. (a) ToF-SIMS secondary ion mapping of ${ }^{2} \mathrm{H}^{-}$on the superclean graphene grown by $\mathrm{Cu}(\mathrm{OAc})_{2}$. (b) ToF-SIMS secondary ion mapping of ${ }^{2} \mathrm{H}^{-}$on unclean graphene grown by $\mathrm{CH}_{4}$. (c) Depth profiles of ${ }^{2} \mathrm{H}^{-}$on transferred graphene film synthesized by $\mathrm{Cu}(\mathrm{OAc})_{2}$ (red) and $\mathrm{CH}_{4}$ (blue) on $\mathrm{SiO}_{2} / \mathrm{Si}$ substrates. 


\section{Decreased PMMA residues on clean regions of graphene surface}

To exclude the interference of parameters during the friction measurement, AFM friction mapping were conducted on the graphene film grown by the two different precursors of ${ }^{12} \mathrm{C}-\mathrm{Cu}(\mathrm{OAc})_{2}$ and ${ }^{13} \mathrm{CH}_{4}$ alternately under identical AFM conditions. As shown in Figure S14, friction of the transferred clean graphene film synthesized from $\mathrm{Cu}(\mathrm{OAc})_{2}$ is much smaller than that of transferred unclean graphene grown from $\mathrm{CH}_{4}$, indicating the close relationship between PMMA residues and cleanness of graphene surface. Here, we used mica as the substrate for graphene transfer and friction measurement to exclude the interference from the surface roughness of the underlying substrate.
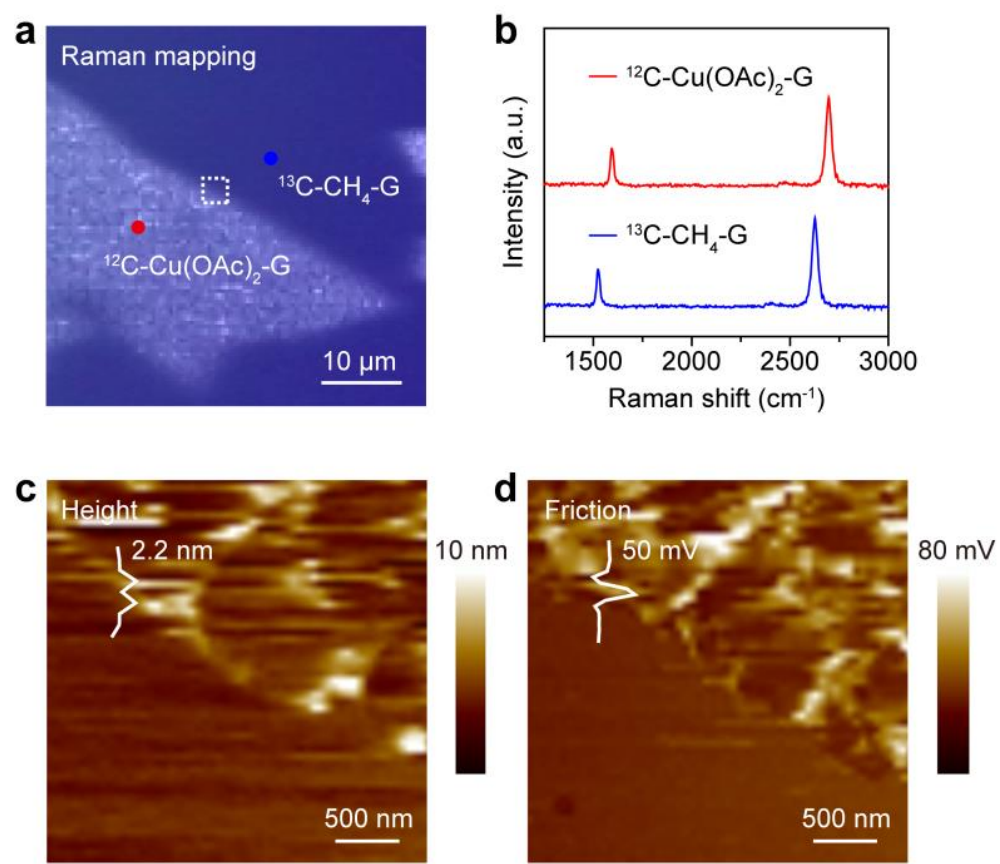

Figure S14. Cleanness and friction difference of graphene grown by the two different precursors sequentially. (a) Raman mapping of graphene grown by ${ }^{12} \mathrm{C}-\mathrm{Cu}(\mathrm{OAc})_{2}$ and ${ }^{13} \mathrm{CH}_{4}$. (b) Raman spectra of the red and blue points marked in (a). (c, d) In-situ height and friction images of the square region marked in (a) with white dotted frame.

\section{Improved light transmittance improvement of the superclean graphene}

Graphene samples grown by $\mathrm{Cu}(\mathrm{OAc})_{2}$ and $\mathrm{CH}_{4}$ were transferred onto quartz substrates with the assistance of PMMA to evaluate their light transmittance. The number of graphene layer was carefully controlled to exclude its influence on the light transmittance. Since the transparency of graphene is 
closely related to the amounts of PMMA residues and amorphous carbon contamination on its surface, ${ }^{4}$ a clear enhancement in light transmittance $(\sim 0.5 \%, 550 \mathrm{~nm})$ was observed in superclean graphene film $(\sim 97.57 \%, 550 \mathrm{~nm})$ than that of unclean counterpart $(\sim 97.06 \%, 550 \mathrm{~nm})$, as shown in Figure $\mathrm{S} 15$.

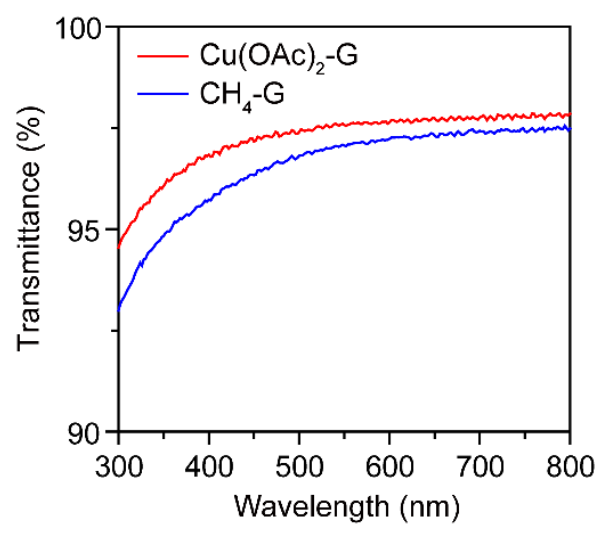

Figure S15. UV-vis spectra of monolayer graphene film grown by $\mathrm{Cu}(\mathrm{OAc})_{2}$ (red) and $\mathrm{CH}_{4}$ (blue) transferred onto quartz substrates.

\section{Evaluation of carrier mobility of graphene film grown by $\mathrm{Cu}(\mathrm{OAc})_{2}$}

To acquire the statistics of the carrier mobility and evaluate the quality of graphene grown by $\mathrm{Cu}(\mathrm{OAc})_{2}$, 12 field effect transistor devices were fabricated and measured at room temperature after we transferred graphene film onto a $\mathrm{SiO}_{2} / \mathrm{Si}$ substrate. Representative transfer curves was presented in Figure $\mathrm{S} 16$ and the carrier mobility value was about $9700 \mathrm{~cm}^{2} /(\mathrm{Vs})$.
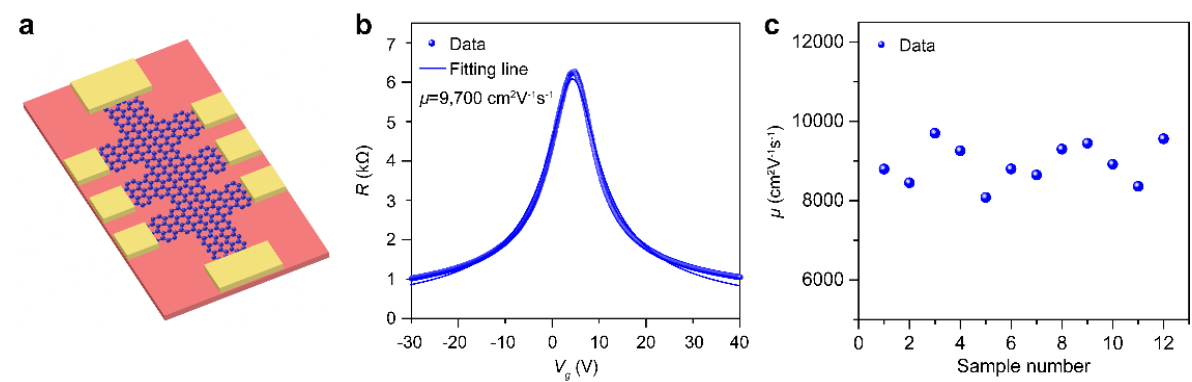

Figure S16. Carrier mobility of graphene film grown by $\mathrm{Cu}(\mathrm{OAc})_{2}$ transferred onto a $\mathrm{SiO}_{2} / \mathrm{Si}$ substrate.

(a) Schematic diagram of graphene device. (b) Representative transfer curve of graphene grown by $\mathrm{Cu}(\mathrm{OAc})_{2}$. (c) Statistic of the measured carrier mobility values. 


\section{Evaluation of sheet resistance of graphene film grown by $\mathrm{Cu}(\mathrm{OAc})_{2}$}

As shown in Figure S17a, superclean graphene sample grown by $\mathrm{Cu}(\mathrm{OAc})_{2}$ was transferred onto 4 in.sized $\mathrm{SiO}_{2} / \mathrm{Si}$ wafer using the conventional PMMA-assisted method and the average sheet resistance of the graphene sample is measured to be $272 \pm 36 \Omega /$ sq (Figure $\mathrm{S} 17 \mathrm{~b}$ ). It should be noted that the graphene conductivity is also related to the transfer-related doping, wrinkle, and breakage, which altogether contribute to the spatial difference in sheet resistance mapping results.

a

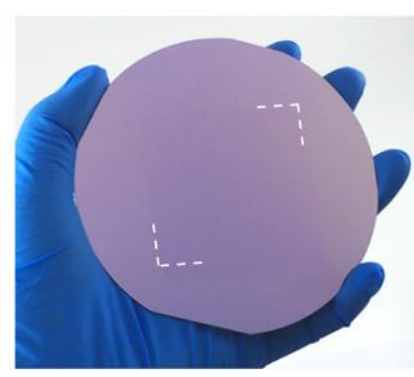

b

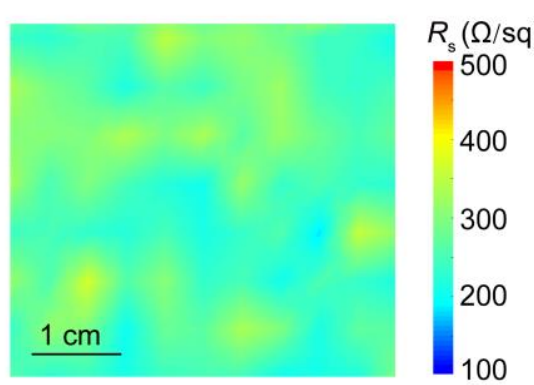

Figure S17. Sheet resistance of the superclean graphene film grown by $\mathrm{Cu}(\mathrm{OAc})_{2}$ transferred onto $\mathrm{SiO}_{2} / \mathrm{Si}$ wafer. (a) Photograph of large-area graphene film transferred onto a 4 in.-sized $\mathrm{SiO}_{2} / \mathrm{Si}$ wafer. (b) Typical sheet resistance mapping results of the superclean graphene film. 


\section{Reference}

(1) Zhang, J.; Lin, L.; Sun, L.; Huang, Y.; Koh, A. L.; Dang, W.; Yin, J.; Wang, M.; Tan, C.; Li, T., Clean Transfer of Large Graphene Single Crystals for High - Intactness Suspended Membranes and Liquid Cells. Adv. Mater. 2017, 29, 1700639.

(2) Li, X.; Cai, W.; Colombo, L.; Ruoff, R. S., Evolution of Graphene Growth on Ni and Cu by Carbon Isotope Labeling. Nano Lett. 2009, 9, 4268-4272.

(3) Wang, X.; Dolocan, A.; Chou, H.; Tao, L.; Dick, A.; Akinwande, D.; Willson, C. G., Direct Observation of Poly (Methyl Methacrylate) Removal from a Graphene Surface. Chem. Mater. 2017, 29 , 2033-2039.

(4) Matkovi-ć, A.; Ralevi-ć, U. İ.; Chhikara, M.; Jakovljevi-ć, M. M.; Jovanovi-ć, D.; Bratina, G.; Gaji-ć, R. İ. Influence of Transfer Residue on the Optical Properties of Chemical Vapor Deposited Graphene Investigated through Spectroscopic Ellipsometry. J. Appl. Phys. 2013, 114, 093505. 